\title{
Penyuluhan bahaya riba di Mushola Al Hidayah Nguter Sukoharjo
}

\author{
Sumadi ${ }^{1, *}$, Tino Feri Efen di $^{1}$, Muhammad Tho'in ${ }^{1}$, Wikan Budi Utami ${ }^{1}$ \\ ${ }^{1}$ Institute Teknologi Bisn is AAS In donesia, Indonesia \\ ${ }^{*}$ Korespondensi (e-mail: ahmadsumadi1924@gmail.com
}

Received: 30-November-21; Revised: 12- December -21; Accepted: 28- December-21

\begin{abstract}
The purpose of this service is to contribute to increasing the level of understanding of the people to provide knowledge to the community, especially in Islamic economic da'wah. This community service aims to advance un derstanding of sharia economics, especially regarding the dangers of usury. It is hoped that the results of this training will provide additional new understanding from the surrounding community. This activity uses the lecture method, discussion, simulation practice, and observation. The lecture method is used in the process of delivering training materials. The expected output targ ets of th is activity are: 1) The community can know and understand the sharia economic system. 2) People get a new und erstanding of the dangers of usury. 3) Furthermore, the community will know and understand how to muamalah, transact in the development of a more Islamic and blessing life.
\end{abstract}

Keywords: Sharia economics, The dangers of usury, Community service, Takmir management

\section{Abstrak}

Tujuan diadakan pengabdian ini adalah dengan latar belakang ing in memberikan sumbangsih dalam mening katkan tingkat pemahaman umat untuk memberikan ilmu peng etahuan kepada masyarakat khususnya dalam dakwah ekonomi syariah. Tujuan pengabdian kepada masyarakat ini adalah untuk penambahan pengetahuan tentang ekon omi syariah, khususnya mengenai bahaya riba. Diharapkan dari hasil pelatihan ini memberikan penambahan pemahaman baru dari masyarakat sekitar. Kegiatan ini dilaksanakan dengan menggunakan metode ceramah, diskusi, praktik simulasi dan observasi. Meto de ceramah digunakan dalam proses penyampaian materi pelatihan. Target luaran yang diharapkan dari kegiatan ini adalah 1) Masyarakat mampu mengetahui dan memahami sistem ekonomi syariah; 2) Masyarakat mendapatkan pemahaman baru tentang bah aya riba; 3) Selanjutnya masyarakat akan mampu mengetahui dan memahami bagaimana bermuamalah, bertransaksi dalam pengembangan kehidupan yang lebih Islami dan berkah.

Kata kunci: Ekonomi syariah, Bahaya riba, Pengabdian masyarakat, Manajemen takmir.

How to cite: Sumadi, S., Efendi, T. F., Tho'in, M., \& Utami, W. B. . (2021). Penyuluhan bahaya riba di Mushola Al Hidayah Nguter Sukoharjo. Penamas: Journal of Community Service, 1(2), 136-142. https://doi.org/10.53088/penamas.v1i2.285

\section{Pendahuluan}

Kemajuan pesat ekonomi syariah adalah salah satu harapan untuk mewujudkan visi Islam tersebut. Hal ini karena ekonomi Islam adalah satu bentuk integral dalam mewadahi, sebagaimana dinyatakan Masrhal (Mahamūd Abū Su'ūd; 1968). Dua kekuatan besar yang mempengaruhi kehidupan dunia, yaitu ekonomi dan agama. Terintegrasikannya dua kekuatan ini dalam satu wadah ekonomi Islam adalah 
merupakan penyatuan kembali bahwa kehidupan ini berhulu dan bermuara pada satu, yaitu Allah SWT (tawhīd). Secara prinsip tauhid adalah menekankan kesatuan alam semesta, kesatuan kebenaran dan pengetahuan serta kesatuan hidup atas dasar dan menuju Allah SWT.

Ekonomi Islam adalah salah satu ilmu yang multi dimensi, interdisiplin, komperhensif, dan saling terintergrasi, meliputi ilmu Islam yang bersumber dari AlQur'an dan Al-Hadist, dan juga ilmu rasional (hasil pemikiran dan pengalaman manusia), dengan ilmu ini manusia dapat mengatasi masalah-masalah keterbatasan sumber daya untuk mencapai falah atau kebahagiaan (Buchari \& Rivai, 2013). Di dalam Al-Qur'an, kata "ar-riba" beserta berbagai bentuk derivasinya disebut sebanyak dua puluh kali, delapan diantaranya berbentuk kata riba itu sendiri. Kata ini digunakan dalam Al-Qur'an dengan bermacam-macam arti, seperti tumbuh, tambah, menyuburkan, mengembang, dan menjadi besar dan banyak. Meskipun berbeda-beda, namun secara umum ia berarti bertambah, baik secara kualitatif maupun kuantitatif (Saeed, 1996).

Riba dilarang karena mempunyai dampak yang negative dari sisi ekonomi Islam. Dampak ekonomi riba adalah dampak inflatoir yang diakibatkan oleh bunga sebagai biaya uang. Semakin tinggi suku bunga, semakin tinggi pula harga yang akan ditetapkan pada suatu barang. Selain itu, dari sisi utang, dengan rendahnya tingkat penerimaan peminjam dan tingginya biaya bunga, akan menjadikan peminjam tidak pernah keluar dari ketergantungan, terlebih lagi bila bunga atas utang tersebut dibungakan, akanterjadi utang yang terus-menerus. Dampak ekonomi riba ini pun mempengaruhi eksistensi dunia perbankan (Yulianti, 2002).

Prinsip-prinsip ekonomi dalam Islam berasal dari ayat Qur'an: "Dan carilah pada apa yang telah dianugerahkan Allah kepadamu (kebahagiaan) negeri akhirat, dan janganlah kamu melupakan bahagiaanmu dari (kenikmatan) duniawi dan berbuat baiklah (kepada orang lain) sebagimana Allah telah berbuat baik kepadamu, dan janganlah kamu berbuat kerusakan di (muka) bumi. Sesungguhnya Allah tidak menyukai orang-orang yang berbuat kerusakan.

Tujuan Islam untuk mewujudkan maslahah dan meraih falah (falah diartikan kesejahteraan, kemuliaan, kesuksesan dan kemenangan). Falah inilah selanjutnya yang menjadi tujuan akhir perilaku ekonomi muslim naik dari aspek dunia maupun aspek akhirat, baik aspek material maupun aspek spiritual. Sehingga kepuasan bukanlah menjadi segala-galanya dalam ekonomi, kepuasan akan diperoleh dari perilaku ekonomi muslim ketika terciptanya maslahah dan secara otomatis akan mencapai falah. Untuk kehidupan dunia falah mencakup tiga hal yaitu kelangsungan hidup kebebasan berkeinginan serta kekuatan dan kehormatan. Sedangkan untuk kehidupan akhirat falah mencakup kelangsungan hidup abadi, kesejahteraan abadi, kemuliaan abadi dan pengetahuan abadi (Sumar'in, 2013).

Peran pendidikan dan pengajaran syiar ekonomi Islam serta praktik bisnis berdasarkan prinsip syariah dewasa ini tidak lagi merupakan keniscayaan, melainkan sudah menjadi kenyataan dan semakin marak. Lembaga ekonomi dan produk-produk 
bisnis Islami bermunculan dan tumbuh di berbagai belahan bumi, bahkan di tengah masyarakat nonmuslim. Begitu pula pelatihan dan pendidikan yang menyiapkan tenaga-tenaga untuk itu. Di kancah akademis, kajian-kajian ilmiah mengenai konsep ekonomi Islam juga terus bergulir dan kian mendalam. Hal ini akibat dari lemahnya sistem ekonomi yang telah ada tidak mampu mensejahterakan masyarakat, di pihak lain terjadinya dikotomi dalam sistem pendidikan yang seolah ekonomi ini hanya milik dari fakultas ekonomi saja pada hal ekonomi merupakan pemenuhan kebutuhan manusia dalam hidupnya, sehingga mestinya pendidikan ekonomi islam perlu diperkenalkan pada semua generasi muda khususnya generasi muslim, bahkan akan lebih baik apabila pendidikan ekonomi islam ini diperkenalkan sejak dini yaitu dari sekolah dasar, hal ini penting karena akan berdampak pada perilaku dimasa yang akan datang. Mengingat penduduk Indonesia mayoritas beragama islam apabila tidak diperkenalkan ekonomi islam sejak dini maka akibatnyaadalah mereka tidak mengerti ekonomi seperti apa yang harus dilakukan, maka tidak heran di negara yang mayoritas penduduknya muslim tetapi dalam perilaku ekonomi keseharianya adalah keluar dari agama yang mereka anut, maka sistem perekonomian syariah menjadi harapan dan bisa dipertimbangkan mana sistem ekonomi yang baik dan harus dilaksanakan agar kesejahteraan masyarakat bisa terwujud (Sumadi, 2018).

Menurut Smith, manusia melakukan kegiatan ekonomi adalah karena dorongan kepentingan pribadi, yang bertindak sebagai tenaga pendorong dan membimbing manusia mengerjakan apa saja asal masyarakat bersedia membayar "Bukan berkat kemurahan tukang daging, tukang pembuat bir, atau tukang pembuat roti kita dapat makan siang," kata Smith "akan tetapi karena mereka memperhatikan kepentingan pribadi mereka. Kita berbicara bukan kepada rasa perikemanusiaan mereka, melainkan pada cinta mereka kepada diri mereka sendiri, dan jangan sekali-kali berbicara tentang keperluan kita, melainkan tentang keuntungan mereka." Motif kepentingan individu yang didorong oleh filsafat liberalisme kemudian melahirkan sistem ekonomi pasar bebas, pada melahirkan ekonomi Kapitalis.

Ekonomi Islam adalah salah satu jawaban dari bagaimana visi Islam direalisasikan, proses realisasi visi Islam adalah mewujudkan ekonomi Islam dalam bentuk realitas. Proses mewujudkan ekonomi Islam yang menjadi sebuah realitas dapat dilihat dari dua wujud yang saat ini sudah berkembang, yaitu wujud teori ekonomi Islam dan praktik ekonomi Islam. Teologi Islam mengajarkan setiap insan terlepas dari kalangan muslim dan kafir untuk melakukan usaha misalnya berupa berdagang dan berbisnis. Hal ini dapat dilakukan dalam bentuk usaha secara perorangan atau dengan cara penggabungan modal dan tenaga misalnya syirkah. Islam juga menganjurkan dalam setiap melakukan transaksi atau kerja sama hendaknya kita menggunakan prinsip Islam dan tidak melakukan bunga atau riba. Pada dasarnya, setiap usaha dan pekerjaan yang menguntungkan seseorang atau masyarakat, yang dapat dikatagorikan sebagai suatu yang halal dan mengandung kebaikan sangatlah ditekankan adanya bentuk kerja sama dan gotong royong.

Mengamalkan prinsip syari'ah dalam semua aspek kehidupan merupakan kewajiban yang telah diperintahkan oleh Allah SWT kepada hamba-hambaNya. Allah 
telah mengharaman riba dalam al-qur'an, sebagaimana keharamannya juga terhdapat pada ayat keharaman khamr, dalam hal ini didalam al-Qur'an terdapatem pat tempat, satu ayat, diturunkan di makkah dan selebihnya diturunkan di Madinah. a) Allah menrurunkan ayat di Makkah yaitu: QS al-Rum: 39 bersamaan dengan keharaman ayat khamr QS; al-Nahl: 67) b) Allah menurunkan ayat di Madinah QS: al-Nisa: 16, dimana Al-qur'an menkisahkan perjalan orang orang Yahudi, Allah telah menharamkan mereka riba, akan tetapi mereka tetap memaknnya, kemudian Allah mengadzab mereka sebab kesalahan mereka. Pada kesempatan yang beriringan datanglah laranganyang kedua kalinya tentang keharaman kahmr, terdapat pada QS: al-Baqarah: 219. c) Allah menurunkan ayatdi Madinah berupa larangan riba bagi pelaku kejahatan yang saling menamabahkan-nambahkan hingga berlipat-lipat dan ini yang pernah ada pada masa Jahiliyah, terdapat pada QS; Ali-Imran: 130. Dan ayat ini beriringan datangannya dengan keharaman riba pada QS; al-Nisa: 43, ayat tersebut diturunkan hendak melakukan shalat dalam keadaan mabuk. Jadi, kedua ayat ini diturunkan untuk melarang dua hal (riba dan khamr), keduanya sudah ada sejak masa Jahiliyah.

Tujuan secara mendasar mengamalkan prinsip-prinsip syari'ah adalah untuk mencapai kemaslahatan hidup di dunia dan akherat (falah). Begitu pula dalam dunia muamalah, perbankan karena tujuan dari menerapkan prinsip-prinsip syari'ah adalah selain untuk mengharap ridha Allah SWT, juga dalam rangka mencapai kemaslahatan di bidang ekonomi. Ketentuan ini mengacu pada kaidah fiqih: "Apabila hukum syara' dilaksanakan, maka pastilah akan tercipta kemas/hatan."

\section{Metode Pengabdian}

Kegiatan pengabdian pada masyarakat ini bertujuan untuk meningkatkan kesadaran masyarakat khususnya jamaah Mushola Al Hidayah Nguter agar paham akan masalah ekonomi syariah khususnya akan bahaya riba. Bentuk kegiatan yang akan dilaksanakan dalam pengabdian kepada masyarakat adalah Memberikan pelayanan dan pemahaman tentang materi ekonimi syariah yang akan diberikan kepada masyarakat setempat. Metode pelaksanaan yang digunakan adalah dengan metode ceramah dan menggunakan tekhnik pendampingan, khusunya melalui takm ir mushola dalam melakukan transfer pengetahuan. Menurut Sidi Gazalba, pengetahuan adalah apa yang diketahui atau hasil pekerjaan tahu. Pekerjaan tahu tersebut adalah hasil dari kenal, sadar, mengerti, dan pandai. Pengetahuan itu adalah semua milik isi pikiran (Bakhtiar, 2014)

Metode pendekatan yang akan dilakukan berdasarkan kesepakatan dengan mitra adalah dengan sosialisasi tentang materi ekonomi syariah. Pelaksanaan kegiatan pengabdian diantaranya yaitu dengan:

a. Koordinasi dengan mitra, penentuan waktu pelaksanaan pengabdian kepada masyarakat, persiapan perlengkapan yang dibutuhkan.

b. Pelaksanaan kegiatan pengabdian kepada masyarakat dengan melakukan sosialisasi program yang dimulai yakni mengenai materi ekonomi syariah 
tentang bahaya riba.

\section{Hasil Pengabdian}

Berdasarkan proses berlangsungnya kegiatan sosialisasi, maka dapat disimpulkan sebagai berikut:

1. Bahwa sosialisasi tersebut sangat membantu masyarakat sekitar masjid. Hal ini mengingat bahwa dipandang dari segi kepahaman agama dan ekonomi mereka masih jauh yang dikehendaki oleh syariat agama. Sehingga dengan mereka memahami bagaimana mengatur keuangan menurut agama terbebas dari bahaya riba, dan diharapkan dapat terwujud cita-cita keluarga yang sakinah mawadah warahmah akan terwujud.

2. Sebagian masyarakat disekitar masjid dengan ekonomi menengah kebawah, maka diperlukan pemahaman tentang ekonomi syariah khususnyabahaya riba sehingga diharapkan dapatmensejahterakan memberikan keberkahan terhadap kehidupan mereka

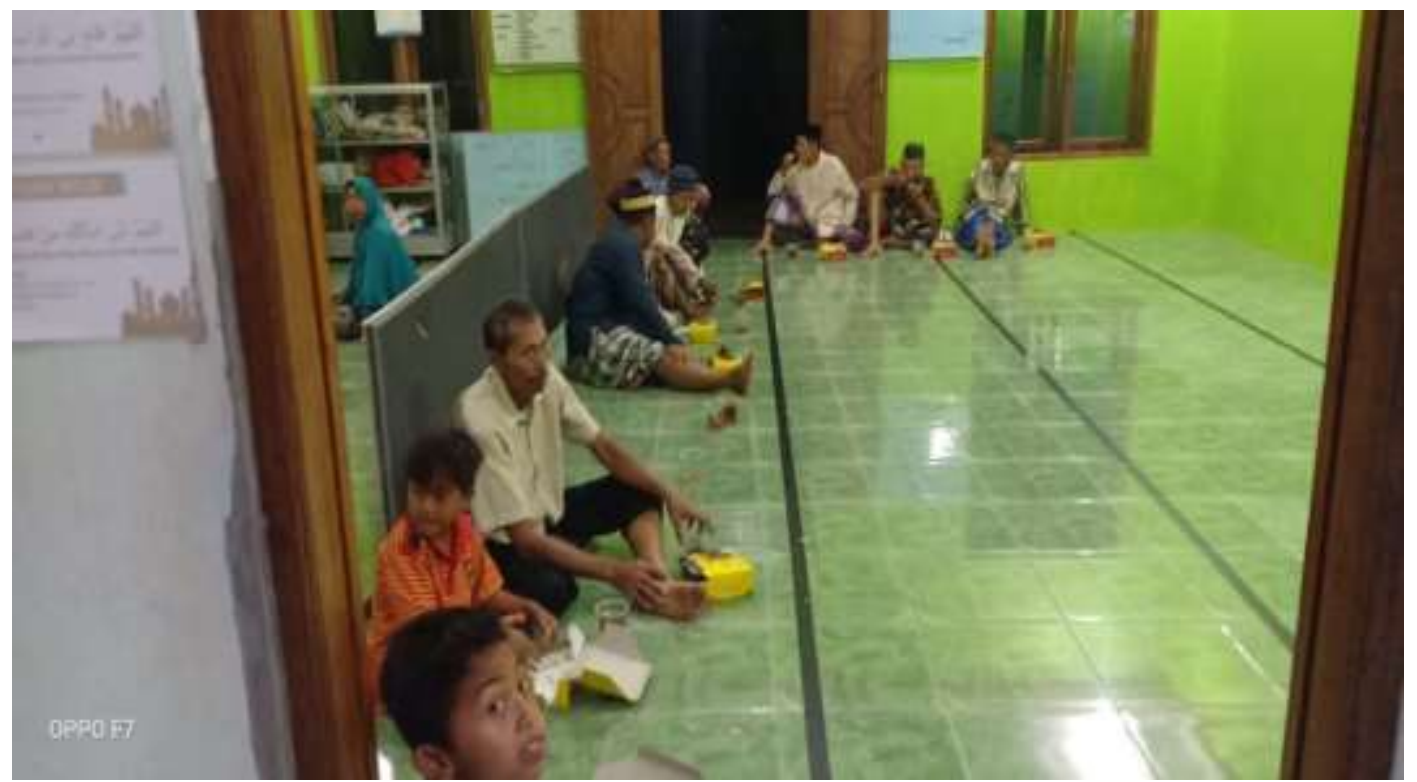

Gambar 1. Kegiatan Sosialisasi di Mushola Al Hidayah Nguter Sukoharjo

Kegiatan PKM Sosialisasi Pelaksanaan dalam memberikan pelayanan dan pemahaman tentang ekonomi syariah khususnya akan bahaya riba, Sejalan dengan program masyarakat sekitar mushola terutama takmir perlu selalu meningkatkan pemahaman tentang peran ekonomi yang Islami, khususnya tentang bahaya riba bagi jamaah, serta senantiasa berusaha terus dalam meningkatkan kemampuan manajemen keuangan keluaga Islami dan pemahaman keluarga sakinah.

Allah SWT telah menurunkan aturan yang memenuhi rasa keadilan manusia. Kaitannya dengan jual-beli dengan kredit, syariat Islam telah menggariskan apa yang disebut dengan Bai' Bitsaman Ajil (BBA). Bai' Bitsaman Ajil merupakan suatu proses perjanjian jual untuk barang tertentu antara pemilik dan pembeli, dimana pemilik barang akan menyerahkan barang seketika, sedangkan pembayaran dilakukan dengan cicilan dalam jangka waktu yang disepakati bersama. Secara ringkas, penjual 
dan pembeli menyepakati total harga barang tersebut, lama waktu pembayarannya, dan pembayaran tiap bulannya tanpa disertai bunga.

Sejak terjadi transaksi, barang tersebut resmi menjadi milik pembeli, hanya saja ia menanggung hutang seharga barang tersebut kepada pihak penjual. Untuk berjagajaga, dapat ditentukan adanya barang jaminan, termasuk barang yang diperjualbelikan tersebut. Bila pihak pem beli tidak dapat memenuhi kewajiban hutangnya dalam waktu yang disepakati tidak dilakukan penentuan hargaulang (repricing) ataupun pemberian sanksi. Salah satu jalan yang ditempuhadalah barang tadi (bila sebagaijaminan) dijual. Hasilnya, sebagian digunakan untuk melunasi sisa hutangnya dan, bila ada, sisanya diberikan kepada pihak pembeli.

Beberapa aturan Allah SWT menegaskan hal ini, diantaranya:

a. Pertama, Firman Allah SWT: "Dan Allah menghalalkan jual beli dan mengharamkan riba” (QS. Al Baqarah [2]: 275). Dalam ayat ini kata Al Bai' bersifat umum. Artinya semua jual beli hukum asalnya halal kecuali ada nash-nash yang menjelaskan keharamannya.

b. Kedua, Imam Bukhari, Muslim, dan Nasai meriwayatkan bahwa Rasulullah SAW pernah membeli bahan makanan dari seorang Yahudi dengan hutang dan beliau memberikan baju besinya sebagai jaminan. Konsep maqasid asy-syariah dalam mewujudkan kemaslahatan manusia yang berupa; agama, jiwa, akal, dan harta (Alkulliyah al-khamsah), dimana inti dari konsep maqasid asy-syariah adalah mencegah kerrusakan dan mendatangkan kemanfaatan.

Agar terbentuk pribadi yang memiliki kemampuan pengelolaan keuangan secara syariah maka disarankan; Pertama, meningkatkan pembentukan masyarakat yang mengetahui keuangan syariah, takm ir diharapkan sebagai pioner dalam memberikan pengertian ekonomi yang Islami kepada para jamaah. Serta selalu memberikan pemahaman dan memotivasi jamaahnya untuk memahami bagaimana mencari rizki yang halalan thoyibah, terbebas dari riba dan mengelolanya dengan baik sesuai dengan aturan agama. Kedua, harus berupaya meningkatkan pemahaman pengaturan keuangan keluarga sesuai aturan agama dan berusaha mengamalkan apa yang telah mereka pahami bersama-sama keluarga serta menyebarluaskan kepada masyarakat lain, sehingga akan terbentuk masyarakat yang aman damai sejahtera, baldatun thoyibatun warobun ghofur.

\section{Kesimpulan}

Berdasarkan hasil kegiatan penyuluhan bahaya riba, maka perlu selalu meningkatkan pemahaman tentang peran ekonomi yang Islami, khususnya tentang bahaya riba bagi jamaah, dan meningkatkan kemampuan manajemen keuangan keluaga Islami dan pemahaman keluarga sakinah. Selain itu untuk agar terbentuk pribadi yang memiliki kemampuan pengelolaan keuangan secara syariah maka disarankan; Pertama, meningkatkan pembentukan masyarakat yang mengetahui keuangan syariah. Kedua, harus berupaya meningkatkan pemahaman pengaturan keuangan keluarga sesuai aturan agama dan berusaha mengamalkan apa yang telah mereka paham i bersamasama keluarga serta menyebarluaskan kepada masyarakat lain. 


\section{Ucapan Terimakasih}

Terima kasih kami sampaikan kepada takmir Mushola Al Hidayah Nguter Sukoharjo yang yang telah membantu pelaksanaan pengabdian dan penyelesaian penulisan naskah.

\section{Referensi}

Saeed, A. (1996). Islamic Banking and Interest: A study of the Prohibition of Riba and its Contemporary Interpretation (Vol. 2). Brill.

Bakhtiar, A. (2014). Filsafat IImu,(Jakarta: PT. Raja Grafindo.

Yulianti, R. T. (2016). Riba dalam Perspektif Ekonomi Islam. Millah: Jurnal Studi Agama, 1(2), 51-70.

Sumar'in, S. (2013). Ekonomi Islam: Sebuah Pendekatan Ekonomi Mikro Perspektif Islam. Yogyakarta: Graha IImu.

Sumadi, S. (2018). Peran Pendidikan dan Pengenalan Sistem Ekonomi Syariah Kepada Generasi Muda di Era Perkembangan Ekonomi Syariah. Jurnal IImiah Edunomika, 2(02).

Buchari, A., \& Rivai, V. (2013). Islamic Economics. Ekonomi Syariah Bukan OPSI Tetapi Solusi, Tth. 